\title{
GARIMPOS DE DIAMANTE NA REGIÃO DE FRANCA, SP
}

\author{
Mário Lincoln De Carlos ETCHEBEHERE \\ Waldir Lopes PONÇANO \\ Rubens Borges da SILVA
}

\begin{abstract}
RESUMO
Este trabalho apresenta um primeiro panorama da explotação de diamantes da região de Franca. Mediante fotoanálise, sobrevôo e trabalhos de campo, foram cadastradas 428 marcas de garimpo, 55 das quais visitadas. Os garimpos se distribuem em aluviões e terraços ao longo dos rios Sapucaizinho, Santa Bárbara e das Canoas. Estima-se uma produção anual da ordem de $1.000 \mathrm{ct}$, dos quais 70 a $80 \%$ de gemas, com tamanhos predominantemente menores que 35 pontos. Os teores, estimadios através de informações de garimpeiros, oscilam entre 0,02 e $0,18 \mathrm{ct} / \mathrm{m}^{3}$, comparáveis com outras regiões diamantíferas do mesmo tipo. A atividade garimpeira envolve problemas de ordem legal, ambiental e humana, que carecem de equacionamento mais adequado.
\end{abstract}

\section{ABSTRACT}

This paper presents an organized set of information concerning the diamantiferous region of Franca (State of São Paulo). The interpretation of aerial photographs, observations from helicopter surveys and field work allowed recognition of 428 indicators of diamond presence; 55 of those have been confirmed. Most of them are scattered along the terraces and alluvial plains of the Sapucaizinho, Santa Barbara and Canoas rivers. An annual production of some $1,000 \mathrm{ct}$ is estimated, mostly (70-80\%) small gems smaller than 35 points. Grades are presumed to vary from 0.02 to $0.18 \mathrm{ct} / \mathrm{m}^{3}$, comparable to currently available values for this kind of placer. Many legal, environmental and human problems related to diamond prospection and exploitation in the area remain to be solved.

\section{INTRODUÇÃO}

Diamantes são conhecidos e garimpados na região francana desde meados do século XIX e, embora este seja o segundo pólo produtor mais antigo do Brasil, poucas referências são feitas ao mesmo na literatura. Aquelas que se relacionam às características, proveniência e produção do diamante são escassas, precárias e procedem, em geral, de relatos verbais.

De modo a levantar a situação geológica, mineira e econômica do diamante francano, o Instituto de Pesquisas Tecnológicas do Estado de São Paulo (IPT), atendendo à solicitação do Programa de Desenvolvimento de Recursos Minerais (PRÓ-MINÉRIO) da Secretaria de Ciência, Tecnologia e Desenvolvimento Econômico do Estado de São Paulo, realizou um diagnóstico preliminar que buscou consubstanciar de modo ordenado e integrado o panorama diamantário da área (IPT, 1990). Este trabalho apresenta os resultados dessa pesquisa, no que diz respeito à atividade garimpeira.

\section{ARCABOUÇO GEOLÓGICO}

A região onde se verifica atividade garimpeira é abrangida por unidades fanerozóicas da Bacia do Paraná e, em menor extensão, por rochas do embasamento pré-cambriano. Sobre essas rochas colocam-se depósitos sedimentares inconsolidados eluviais, coluviais e aluviais, sendo estes últimos os mais importantes em termos diamantíferos.

O embasamento pré-cambriano inclui quartzitos e xistos, fortemente cisalhados, atribuídos ao Grupo Canastra por BARBOSA et al. (1970). As unidades da Bacia do Paraná incluem arenitos, diamictitos e lamitos de ambiente fluvioglacial da Formação Aquidauana (Permiano), arenitos lamíticos fluviais da Formação Pirambóia (Triássico), arenitos eólicos da Formação Botucatu (Triássico), basaltos da Formação Serra Geral (Jurássico-Cretáceo), diques e sills mesozóicos de diabásio, além de arenitos lamíticos, arenitos conglomeráticos, lamitos e conglomerados fluviais do Grupo Bauru (CretáceoEocenozóico?). 


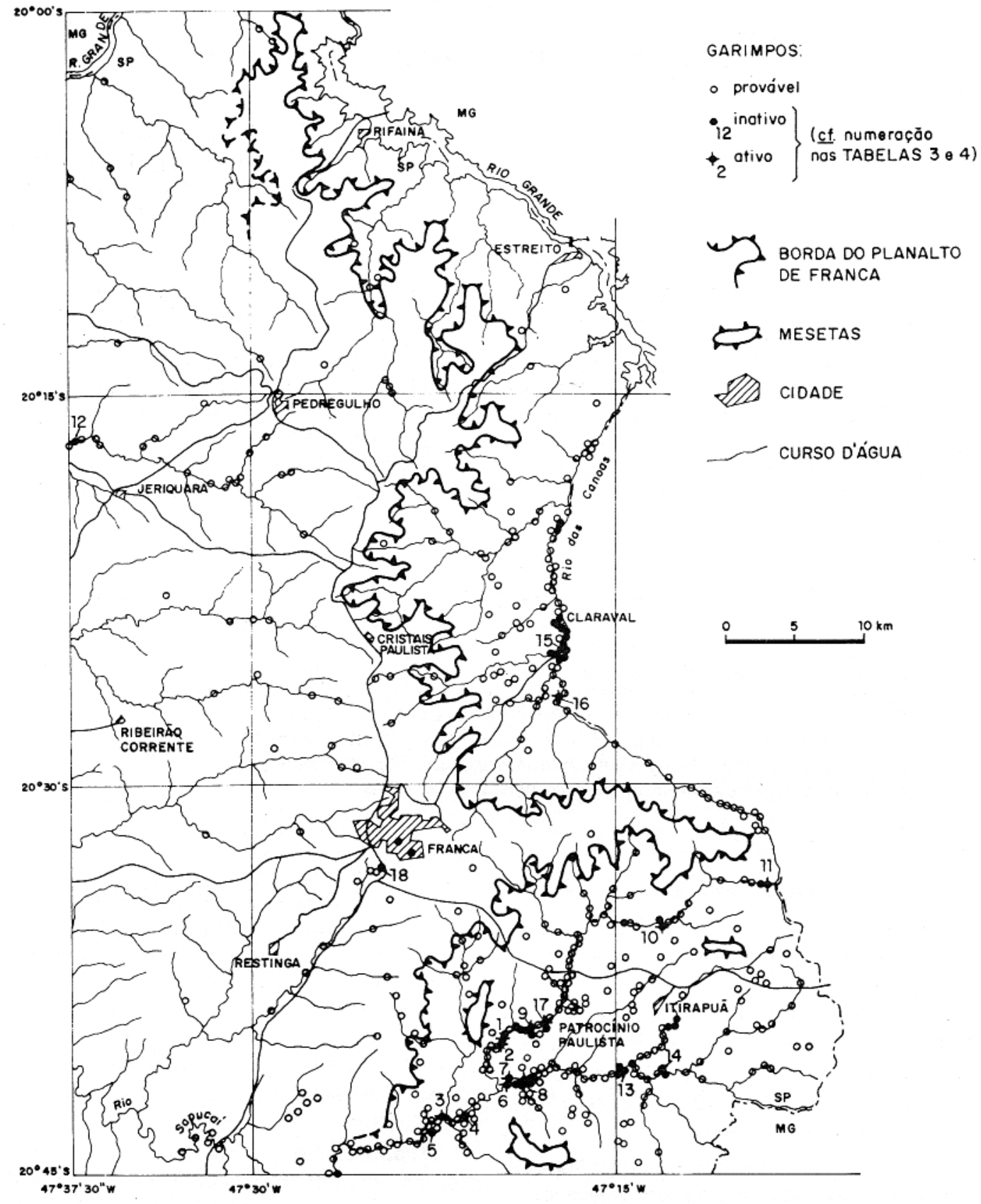

FIGURA 1 - Mapa de garimpos. 
TABELA 1 - Cômputo das marcas de garimpagens.

\begin{tabular}{|l|r|r|r|r|r|}
\hline \multirow{2}{*}{ MUNICÍPIO } & \multicolumn{3}{|c|}{ No. DE GARIMPOS } & \multirow{2}{*}{ SUBTOTAL } & $\%$ \\
\cline { 2 - 4 } & PROVÁVEL & INATIVO & ATIVO & & \\
\hline BATATAIS & 4 & - & - & 4 & 0,9 \\
CRISTAIS PTA. & 53 & 11 & - & 64 & 15,0 \\
FRANCA & 63 & 8 & 1 & 72 & 16,8 \\
IGARAPAVA & 5 & - & - & 5 & 1,2 \\
ITIRAPUÃ & 35 & 5 & - & 40 & 9,3 \\
JERIQUARA & 3 & 1 & - & 4 & 0,9 \\
PATROCÍNIO PTA. & 146 & 20 & 9 & 175 & 40,9 \\
PEDREGULHO & 33 & - & - & 33 & 7,7 \\
RESTINGA & 28 & - & - & 28 & 6,5 \\
RIB. CORRENTE & 1 & - & - & 1 & 0,2 \\
RIFAINA & 2 & - & - & 2 & 0,5 \\
TOTAL & 373 & 45 & 10 & 428 & 99,9 \\
\hline \multicolumn{2}{|c|}{$\%$} & 87,1 & 10,5 & 2,3 & \multicolumn{2}{c}{} \\
\hline
\end{tabular}

É importante salientar que a sedimentação pós-basáltica se processou em decorrência da atuação do Soerguimento do Alto Paranaíba (HASUI et al., 1975), num sistema de rios anastomosados fluindo no rumo sudoeste, dando origem a leques aluviais coalescentes, com raros depósitos interleques ou em partes distais do sistema. Durante estes eventos teria vigido clima árido ou semi-árido, atestado através da presença de argilas esmectíticas e calcedônia lengthslow. De acordo com IPT (1990), o Grupo Bauru se apresenta, na área, como a mais provável fonte imediata de diamantes para os depósitos aluvionares e de terraço, atualmente garimpados, não descartando, porém, outras providências e, mesmo, fontes múltiplas.

O Soerguimento do Alto Paranaíba apresenta diversas manifestações ígneas sob a forma de chaminés alcalinas, tais como Araxá, Salitre e Tapira (70-100 Ma, K/Ar), diatremas kimberlíticos senonianos, derrames e tufos da Formação Patos (idade mínima de $70 \mathrm{Ma}$ ) e lavas ugandíticas na região de Sacramento (MG) com idades mínimas de 44 Ma em datações K/Ar (cf. HASUI, 1967; HASUI \& CORDANI 1968; ALMEIDA, 1986).

Em termos geomorfológicos, a área de interesse é composta por dois níveis planálticos, bastante erodidos, a saber: o Planalto de Franca (cotas entre 800-1.000 m), que deve corresponder à Superfície Japi de ALMEIDA (1964), e o nível colinoso que margeia o rio Grande (cotas de 650-750 m), correlato à Superfície Neogênica (MARTONNE, 1940). Separando ambos os níveis planálticos, destacam-se escarpas festonadas e diversos relevos residuais de peões e mesetas.
A maior concentração de garimpos se dá ao longo dos rios Sapucaizinho, Santa Bárbara e Canoas, que fluem sobre um espesso sill de diabásio, dissecando o nível planáltico rebaixado atribuído à Superfície Neogênica.

\section{CADASTRAMENTO DOS GARIMPOS}

\subsection{Método de trabalho}

Um primeiro registro de locais de possível atividade garimpeira foi realizado através da interpretação de fotografias aéreas. Foram analisados 400 pares estereoscópicos de fotos aéreas na escala aproximada de 1:25.000, obtidas nos levantamentos de 1962 e 1971, realizados, respectivamente, pela Secretaria de Agricultura do Estado de São Paulo e pelo Instituto Brasileiro do Café - Grupo Executivo de Racionalização da Agricultura (IBC-GERCA).

Os pares estereoscópicos foram examinados com o auxílio de lupa, o que possibilitou a detecção de cavas com áreas menores que $4 \mathrm{~m}^{2}$. Isto foi possível graças ao padrão geométrico, geralmente retangular, da grande maioria dos pontos garimpados ou testados para garimpo, perceptível mesmo quando as cavas se interligam ou se acham degradadas e cobertas por vegetação.

Seguiu-se uma etapa de campo, com o cadastramento dos principais garimpos da área, em especial os ativos, dos quais se podem tirar maiores informações qualitativas e quantitativas (tipo e quantidade de diamantes, teores, capeamento estéril, minerais-satélites etc.), além de permitir amostrar os níveis de interesse. 
TABELA 2 - Taxas de crescimento dos pontos de garimpagem.

\begin{tabular}{|c|c|c|c|c|c|}
\hline \multirow{2}{*}{ CURSO D'ÁGUA } & \multicolumn{2}{|c|}{ № DE GARIMPOS } & \multirow{2}{*}{$\begin{array}{l}\text { INCREMENTO } \\
71-62\end{array}$} & \multirow{2}{*}{$\begin{array}{c}\text { TAXA DE } \\
\text { INCREMENTO } \\
\% \\
\end{array}$} & \multirow{2}{*}{$\begin{array}{l}\text { PROJEÇÃO } \\
\text { PARA } 1990\end{array}$} \\
\hline & 1962 & 1971 & & & \\
\hline $\begin{array}{l}\text { RIO SAPU- } \\
\text { CAIZINHO } \\
\text { (cerca de } 30 \mathrm{~km} \\
\text { de leito) }\end{array}$ & 34 & 48 & 14 & 41 & 78 \\
\hline $\begin{array}{l}\text { RIO STA. } \\
\text { BÁRBARA } \\
\text { (cerca de } 35 \mathrm{~km} \\
\text { de leito) }\end{array}$ & 49 & 72 & 23 & 47 & 120 \\
\hline $\begin{array}{l}\text { RIO DAS } \\
\text { CANOAS } \\
\text { (cerca de } 50 \mathrm{~km} \\
\text { de leito) }\end{array}$ & 57 & 63 & 6 & 11 & 76 \\
\hline
\end{tabular}

Também foi realizado um sobrevôo de helicóptero nas bacias hidrográficas dos rios das Canoas, Sapucaizinho e baixo Santa Bárbara, que permitiu identificar a presença de garimpos ativos ainda não cadastrados, bem como observar as principais várzeas, discernindo-se os trechos garimpados daqueles intactos.

\subsection{Mapa de garimpos}

Os principais setores garimpados são o Rio das Canoas, próximo a Claraval, e os rios Sapucaizinho e Santa Bárbara, estes ao longo de seus cursos em toda a área estudada. Em menor número, ocorrem marcas de garimpagem no reverso do Planalto de Franca, inclusive dentro do sítio urbano da cidade homônima (FIGURA 1).

Os garimpos foram classificados em três categorias: prováveis (quando não se obteve comprovação cabal no campo), ativos e inativos (com relação à época do levantamento). Sua distribuição por município é apresentada na TABELA 1 .

Ressalte-se que nos setores mais intensamente garimpados foi realizada fotoanálise em levantamentos de 1962 e 1971, a fim de se caracterizar a expansão da atividade garimpeira. Os resultados obtidos são apresentados na TABELA 2, destacando-se um crescimento de pontos de garimpo da ordem de $33 \%$ em 9 anos. Caso essa taxa tenha-se mantido, é possível que os pontos de garimpagem e cavas de pesquisa ("faiscagem") da área atinjam, atualmente, cerca de 700 .

Grande parte dos pontos assinalados no mapa de garimpo corresponde a pequenas cavas exploratórias, em geral com superfície menor que
$6 \mathrm{~m}^{2}$, feitas de modo a alcançar o cascalho e obter alguns metros cúbicos para lavagem. Caso não fossem encontrados diamantes (em geral pequenos, designados "chibius") ou mineraissatélites ("formas"), considerados bons indicadores, a cava era abandonada.

\section{CARACTERÍSTICAS DOS GARIMPOS}

Na grande maioria dos pontos de garimpo marcados na FIGURA 1 não foi possível obter muitas informações, salvo a própria constatação da atividade garimpeira, tamanho da cava e espessura mínima de cobertura estéril. Esta carência decorre do abandono das cavas, que são alagadas, entulhadas por detritos ou invadidas pelo mato.

Dados mais relevantes foram obtidos nos garimpos ativos, onde se conseguiu entrevistar os garimpeiros. Ainda assim, em face da situação irregular dos garimpos, muitas informações foram passadas de forma vaga ou pouco conclusiva.

Os dados de espessuras de capeamento e de conglomerado foram obtidos por observações de campo e os teores de diamante através de informações de garimpeiros, devendo, pois, ser vistos com reservas.

Uma síntese das informações cadastradas encontra-se nas TABELAS 3 e 4; nota-se uma escassez relativamente a dados de produção diamantífera, volumes lavrados de minério e capeamento. Para efeito de comparação, os valores obtidos foram integrados na TABELA 5, ao lado de dados coletados na literatura acerca de outros garimpos e minas. 
Os garimpos de maior porte estão situados nas várzeas, valendo destacar dois aspectos no que se refere à intensidade de explotação, a saber:

a) as amplas várzeas do baixo Rio Santa Bárbara mostram numerosas lagoas de contornos angulosos, provavelmente derivadas de antigos garimpos;

b) as planícies aluvionares do Rio das Canoas, a jusante de Claraval (MG), mostram-se, por sua vez, pouco trabalhadas, predominando catas em terraços; e

c) o Rio Sapucaizinho apresenta pequenos bolsões aluvionares que vêm sendo intensamente garimpados.

No que se refere aos terraços, constata-se um predomínio de cavas nos depósitos mais próximos das drenagens, balizados, tanto na região de Patrocínio Paulista quanto na de Claraval, pela cota aproximada de $710 \mathrm{~m}$. Acima dessa cota, mais distantes dos cursos d'água, há menos garimpos.

O cadastramento de campo permitiu estimar que cerca de 15 garimpeiros continuam ativos, ainda que em situação irregular perante o DNPM, aos quais se agregam auxiliares temporários e trabalhadores de fins de semana.

A produção anual estimada de diamantes da região, em território paulista, é da ordem de $1.000 \mathrm{ct}$. A se considerar a produção de garimpos do lado mineiro (não estudados), este número pode ascender a $3.000 \mathrm{ct} / \mathrm{ano}$, valor que, se considerado médio para toda a produção histórica da área, permite admitir um montante extraído superior a $400.000 \mathrm{ct}$.

A literatura traz poucas informações acerca das características dos diamantes de Franca. Tais dados e as observações de campo indicam um predomínio de diamantes pequenos, de boa qualidade, em geral bem arredondados e com superfície fcsca. Em menor número, são encontrados diamantes maiores, amarelados ou com imperfeições. Das gemas que podem ser aproveitadas para lapidação, cerca de $40 \%$ são compostas de até 10 pedras por quilate ("fazenda fina"), $30 \%$ correspondem a grupos de 3 pedras por quilate e as restantes a pedras maiores ("chips") - GONÇALVES \& ALGARTE (1988).

A presença de diamantes menos rolados, com faces cristalográficas bem definidas, a ocorrência de certos minerais pesados, bem como o contexto geológico e tectônico regional permitem suspeitar da existência de mais de uma fonte diamantífera, até mesmo do tipo primário (IPT, 1990).
Entre os danos que a atividade garimpeira causa ao meio ambiente, incluem-se a degradação de terras cultiváveis e o assoreamento dos cursos d'água.

\section{TÉCNICAS DE LAVRA E PROSPECÇÃO}

O primeiro aspecto que se destaca nos garimpos da região de Franca é seu caráter rudimentar, seja na prospecção, avaliação ou lavra dos depósitos, freqüentemente com efeitos nocivos ao meio ambiente.

A prospecção de novos depósitos é feita de modo empírico, quase sempre ao lado de cavas antigas ou em trechos de aluviões anteriormente explotados. Em diversos pontos verificou-se mais de uma fase de garimpagem, pois, ao lado de cavas entulhadas e pilhas de cascalho já coberto por vegetação, foram observadas cavas mais recentes.

Em geral, os garimpos se limitam aos leitos dos rios, às várzeas ("grupiaras") e aos baixos terraços ("manchões" ou "monchões"), sendo raras as explotações em outros depósitos. As rupturas de declividade que caracterizam os terraços, chamadas "lombas", constituem um dos critérios utilizados no balizamento de cavas exploratórias. Nesta etapa, os garimpeiros utilizam uma haste pontiaguda de aço, com 1,5 ou $2 \mathrm{~m}$ de comprimento, para "sondar" o terreno e verificar a possível presença de cascalho. Eles mostram notável experiência com este tipo de sondagem, discernindo habilmente o topo dos conglomerados sotopostos a pacotes aluvionares ou coluvionares e eventuais níveis de crostas lateríticas ("cascas") através do som da percussão.

Constatada a presença de cascalho, passase à abertura de uma cava, em geral quadrada, com 2 ou $3 \mathrm{~m}$ de lado, para a obtenção de alguns metros cúbicos de material para apuração. Em caso de sucesso (pelo menos um diamante pequeno, "chibiu"), dá-se prosseguimento à lavra, mantendo-se o padrão geométrico nas escavações.

Nos garimpos de leitos de cursos d'água, procede-se, às vezes, à construção de canais de desvio ("virada"), conforme se pôde observar nos rios Sapucaizinho e Santa Bárbara. Quando a vazão se torna menor, nas estiagens, podem ser construídas ensecadeiras ("recuados").

$\mathrm{Na}$ prospecção levam-se em conta os minerais-satélites, "formas", que acompanham o diamante por similaridade densimétrica ou de resistência ao desgaste. Uma lista desses minerais, incluindo sua designação pelos garimpeiros, é dada na TABELA 6. 
TABELA 3 - Características dos garimpos cadastrados (I).

N

\begin{tabular}{|c|c|c|c|c|c|c|c|c|c|c|}
\hline \multirow[b]{2}{*}{ PONTO } & \multirow[b]{2}{*}{ CURSO D'ÁGUA } & \multirow[b]{2}{*}{ FEIÇÃO } & \multirow[b]{2}{*}{ COTA } & \multicolumn{2}{|c|}{ CAVA } & \multicolumn{4}{|c|}{ CASCALHO } & \multirow{2}{*}{$\begin{array}{l}\text { PRODUÇÃO } \\
\text { DE } \\
\text { DIAMANTES }\end{array}$} \\
\hline & & & & ÁREA & PROFUND. & EMBASAMENTO & ESPESSURA & COMPOSIÇÃO & SATÉLITES & \\
\hline \multirow[t]{2}{*}{1} & \multirow[t]{2}{*}{ Rio Sapucaizinho } & \multirow[t]{2}{*}{ Terraço } & \multirow[t]{2}{*}{$710 \mathrm{~m}$} & $2 \mathrm{~m}^{2}$ & $2 \mathrm{~m}$ & diabásio alterado & $20-40 \mathrm{~cm}$ & $\begin{array}{l}\text { basalto, arenito, quartzi- } \\
\text { to, quartzo, calcedônia }\end{array}$ & $\begin{array}{l}\text { quartzo em paliçada, tur- } \\
\text { malina, calcedônia }\end{array}$ & desconhecida \\
\hline & & & & $15 \mathrm{~m}^{2}$ & $2 \mathrm{~m}$ & diabásio alterado & $20-40 \mathrm{~cm}$ & $\begin{array}{l}\text { basalto, arenito, quartzi- } \\
\text { to, quartzo, calcedônia }\end{array}$ & $\begin{array}{l}\text { quartzo em paliçada, tur- } \\
\text { malina, calcedônia }\end{array}$ & desconhecida \\
\hline \multirow[t]{2}{*}{2} & \multirow[t]{2}{*}{ Rio Sapucaizinho } & \multirow[t]{2}{*}{ Terraço } & \multirow[t]{2}{*}{$710 \mathrm{~m}$} & $50 \mathrm{~m}^{2}$ & $1,5 \mathrm{~m}$ & diabásio alterado & $1 \mathrm{~m}$ & $\begin{array}{l}\text { basalto, quartzito, } \\
\text { quartzo }\end{array}$ & $\begin{array}{l}\text { quartzo em paliçada, ita- } \\
\text { birito, turmalina, gorcei- } \\
\text { xita + goethita, crisobe- } \\
\text { rilo, corindon, goethita } \\
+ \text { quartzo }\end{array}$ & $\begin{array}{l}1,5 \text { ct de pequenos dia- } \\
\text { mantes }\end{array}$ \\
\hline & & & & $25 \mathrm{~m}^{2}$ & - & diabásio alterado & - & $\begin{array}{l}\text { basalto, quartzito, } \\
\text { quartzo }\end{array}$ & $\begin{array}{l}\text { quartzo em paliçada, ita- } \\
\text { birito, turmalina, gorcei- } \\
\text { xita + goethita, crisobe- } \\
\text { rilo, corindon, goethita } \\
+ \text { quartzo }\end{array}$ & $\begin{array}{l}1,5 \text { ct de pequenos dia- } \\
\text { mantes }\end{array}$ \\
\hline 3 & Rio Sta. Bárbara & Terraço & $710 \mathrm{~m}$ & - & - & $\begin{array}{c}\text { solo residual da Fm. Pi- } \\
\text { rambóia }\end{array}$ & - & - & - & $\begin{array}{c}0,2 \text { ct de pequenos dia- } \\
\text { mantes }\end{array}$ \\
\hline 4 & Rio Sta. Bárbara & Terraço & $710 \mathrm{~m}$ & - & - & $\begin{array}{l}\text { solo residual da Fm. Pi- } \\
\text { rambóia }\end{array}$ & $30 \mathrm{~cm}$ & - & $\begin{array}{l}\text { gorceixita }+ \text { goethita }+ \\
\text { quartzo, corindon, tur- } \\
\text { malina, cianita, rutilo, } \\
\text { quartzo, crisoberilo }\end{array}$ & $\begin{array}{l}\text { alguns diamantes me- } \\
\text { nores que } 0,15 \mathrm{ct}\end{array}$ \\
\hline 5 & Rio Sta. Bárbara & Terraço & $710 \mathrm{~m}$ & - & - & - & - & $\begin{array}{l}\text { quartzito e quartzo, ma- } \\
\text { triz arenosa com cimen- } \\
\text { tação limonítica }\end{array}$ & - & - \\
\hline 6 & Rio Sta. Bárbara & Várzea & - & $400 \mathrm{~m}^{2}$ & - & diabásio & $0,3-1,5 \mathrm{~m}$ & - & - & $\begin{array}{c}6 \mathrm{ct} \text {, sendo } 1 \text { pedra de } \\
4,5 \mathrm{ct}\end{array}$ \\
\hline 7 & Rio Sta. Bárbara & Terraço & $710 \mathrm{~m}$ & - & - & Arenito Pirambóia & - & - & - & - \\
\hline \multirow[t]{2}{*}{8} & \multirow[t]{2}{*}{ Rio Sta. Bárbara } & \multirow[t]{2}{*}{ Terraço } & \multirow[t]{2}{*}{$710 \mathrm{~m}$} & $15.000 \mathrm{~m}^{2}$ & até $6 \mathrm{~m}$ & - & - & - & - & - \\
\hline & & & & 3 de $30 \mathrm{~m}^{2}$ & até $6 \mathrm{~m}$ & - & - & $\begin{array}{l}\text { quartzo, quartzito e } \\
\text { arenito }\end{array}$ & - & - \\
\hline
\end{tabular}


TABELA 4 - Características dos garimpos cadastrados (II).

\begin{tabular}{|c|c|c|c|c|c|c|c|c|c|c|}
\hline \multirow[b]{2}{*}{ PONTO } & \multirow[b]{2}{*}{ CURSO D'ÁGUA } & \multirow[b]{2}{*}{ FEIÇÃO } & \multirow[b]{2}{*}{ COTA } & \multicolumn{2}{|c|}{ CAVA } & \multirow[b]{2}{*}{ EMBASAMENTO } & \multicolumn{3}{|c|}{ CASCALHO } & \multirow{2}{*}{$\begin{array}{c}\text { PRODUÇÃO } \\
\text { DE } \\
\text { DIAMANTES }\end{array}$} \\
\hline & & & & ÁREA & PROFUND. & & ESPESSURA & COMPOSIÇÃO & SATÉLITES & \\
\hline 9 & Rio Sapucaizinho & - & - & $600 \mathrm{~m}^{2}$ & até $9 \mathrm{~m}$ & diabásio & $2 \mathrm{~m}$ & $\begin{array}{l}\text { diabásio, arenito, areni- } \\
\text { to silicificado, quartzo }\end{array}$ & - & 150 ou $450 \mathrm{ct}$ \\
\hline 9 & Rio Sapucaizinho & Várzea & - & - & - & diabásio & $1 \mathrm{~m}$ & - & - & $\begin{array}{l}9 \text { diamantes de até } \\
0,3 \mathrm{ct} \text { e um de } 1,2 \mathrm{ct}\end{array}$ \\
\hline 10 & Rib. São Tomé & Várzea & - & - & - & Arenito Pirambóia & $80 \mathrm{~cm}$ & - & rutilo, cianita & $\begin{array}{l}49 \mathrm{ct} \text { de várias pedras } \\
\mathrm{em} \mathrm{abril} / 90 \mathrm{e} \mathrm{uma} \mathrm{de} \\
19 \mathrm{ct} \mathrm{em} \mathrm{junho/90}\end{array}$ \\
\hline 11 & Rib. Água Limpa & Terraço (?) & $770 \mathrm{~m}$ & $40 \mathrm{~m}^{2}$ & $1,2 \mathrm{~m}$ & basalto & $40 \mathrm{~cm}$ & $\begin{array}{l}\text { quartzito, quartzo, basal- } \\
\text { to, calcedônia, arenito } \\
\text { silicif. }\end{array}$ & - & $\begin{array}{l}\text { poucos diamantes, } \\
\text { pequenos }\end{array}$ \\
\hline 12 & Rio Sta. Bárbara & Terraço & $720 \mathrm{~m}$ & $40.000 \mathrm{~m}^{2}$ & - & - & - & - & - & - \\
\hline 13 & Rio Sta. Bárbara & - & $730 \mathrm{~m}$ & $\begin{array}{l}\text { diversas } \\
\left(12 \mathrm{~m}^{2}\right.\end{array}$ & $3 \mathrm{~m}$ & - & - & - & - & - \\
\hline 14 & Rio Canoas & Terraço & $710 \mathrm{~m}$ & $1.500 \mathrm{~m}^{2}$ & - & - & $80 \mathrm{~cm}$ & $\begin{array}{l}\text { quartzito, basalto, li- } \\
\text { monita }\end{array}$ & - & $\begin{array}{l}500 \text { diamantes me- } \\
\text { nores que } 0,4 \mathrm{ct} \text { e um } \\
\text { de } 6,45 \mathrm{ct}\end{array}$ \\
\hline 15 & Rio Canoas & - & - & $\begin{array}{c}3 \mathrm{de} 25 \mathrm{~m}^{2} \\
\text { cada }\end{array}$ & - & - & - & $\begin{array}{l}\text { diabásio, quartzito, } \\
\text { arenito }\end{array}$ & - & - \\
\hline \multirow[t]{2}{*}{16} & \multirow[t]{2}{*}{ Rio Sapucaizinho } & \multirow[t]{2}{*}{-} & \multirow[t]{2}{*}{$710 \mathrm{~m}$} & - & - & - & $0,5-1 \mathrm{~m}$ & arenito, quartzito & - & - \\
\hline & & & & $\begin{array}{l}\text { várias com } \\
\text { menos de } \\
15 \mathrm{~m}^{2} \text { cada }\end{array}$ & - & - & $20 \mathrm{~cm}$ & - & - & $\begin{array}{l}2 \text { diamantes de } 0,15 \\
\text { ct cada }\end{array}$ \\
\hline 17 & Rib. dos Bagres & Terraço & - & - & - & basalto & $10-40 \mathrm{~m}$ & - & - & - \\
\hline
\end{tabular}


Outro indício considerado relevante é a presença de blocos ou matacões ("emburrados"), que indicariam cascalho com maior probabilidade de ser diamantífero. Cascalhos pouco espessos e sem "emburrados" são chamados de "pururuca".

Pode-se considerar que tais processos de prospecção e avaliação se aproximam dos adotados na lavra sistemática. Entretanto, dela divergem substancialmente por não levarem em conta, de modo organizado e sistemático, o conjunto da área passível de explotação.

As catas de pesquisa podem ser consideradas germes de escavações maiores, caso sejam encontrados diamantes. A explotação e; etiva inclui a remoção do capeamento estéril. em geral arenoso, friável e com espessura de ate $8 \mathrm{~m}$, que é empilhado ao lado ou no interior da própria cava; o cascalho subjacente é desmontado por jatos d'água ou com auxílio de pás ou picaretas. Em garimpos de maior porte, ambos os desmontes podem ser realizados com o concurso de tratores ou retroescavadeiras, em geral alugados por tarefa.

O cascalho desmontado, quando em pequenos volumes, é transportado até o local de apuração, que geralmente se situa junto a um curso d'água ou desvio. Em certos casos, pode-se proceder a um peneiramento na própria cava, com peneira com malha de até $3 \mathrm{~cm}$ ("suruca"), ou a uma lavagem em calha perfurada ("ralador').

A operação seguinte é a deslamagem do cascalho ("desengomagem"), que pode ser feita na própria cava, onde o material é lavado em calhas ou valas que conduzem ao ponto final de apuração ou a um pátio ou bacia apropriados. Nesta operação, os blocos e calhaus são separados manualmente.

As calhas têm na extremidade um tambor ("fervedouro") ou peneira vibratória, onde se dá a última concentração. Alguns "fervedouros" dão saída para novas calhas, formando conjuntos com dois ou mais jogos de tambores de concentração, terminando num tanque ou caixa maior. O material retido nestes tambores e tanques é retirado com pás e empilhado ao lado do ponto final de apuração. Em alguns casos, chega a ser utilizada uma bica do tipo canadense ou uma bica com peneira acoplada. O emprego de bombas de sucção (6 ou 8') foi também observado.

A apuração final é executada com um jogo de duas ou três peneiras com malhas de 6 ou 3 e $1,5 \mathrm{~mm}$, parcialmente mergulhadas em água. A concentração é obtida por uma combinação de movimentos circulares e oscilatórios, de tal maneira que os elementos mais densos são conduzidos para o centro da peneira. Esta operação dura de 3 a 5 minutos; as peneiras são posteriormente emborcadas no solo, ficando o material mais pesado por cima. A apuração do diamante é feita por observação visual, sendo os fragmentos removidos cuidadosamente com o auxílio de uma palheta.

As atividades de decapeamento, desmonte de cascalho, deslamagem e apuração não são contínuas. Os garimpeiros se concentram temporariamente em cada uma dessas etapas.

Os garimpos menores são, em geral, explotados de modo intermitente, em fins de semana ou em épocas de estiagem; nos demais períodos os garimpeiros exercem outras atividades. Alguns moram temporária ou permanentemente ao lado das catas, em condições precárias de habitação, higiene e conforto.

Os garimpos maiores são liderados por um garimpeiro ("dono do serviço") que pode contratar temporariamente alguns empregados ("diaristas") para o desmonte, deslamagem ou mesmo apuração. Este paga ao proprietário da terra um percentual subre o valor de venda dos diamantes apurados, que varia de $10 \%$ para as pedras inferiores a $1 \mathrm{ct}$ a $20 \%$ para as maiores.

\section{PERSPECTIVAS}

As atividades garimpeiras na região de Franca são amparadas no conhecimento empírico dos garimpeiros e estão, em termos legais, perante o DNPM, em situação irregular. Não raro, também, os garimpos danificam o meio ambiente, assoreando cursos d'água e tornando improdutivos vários tratos de terra. Estes fatos, somados às iniciativas das municipalidades da região francana no sentido de aí viabilizar a implantação de um pólo diamantário - congregando aspectos mineiros, industriais, econômicos, didáticos e alfandegários - e à necessidade de melhor se conhecer o potencial diamantífero da área, têm levado ao surgimento de propostas de mudança do caráter mineiro regional, com a passagem do garimpo para a lavra empresarial, de preferência em termos cooperativos (IPT, 1990).

Grandes trechos de terraços e aluviões atuais permanecem intatos o que - aliado ao fato de os teores estimados para a região (oscilantes entre 0,02 e $0,18 \mathrm{ct} / \mathrm{m}^{3}$ ) serem compatíveis com os de outras áreas mineradas - suscita oportunidades de investimentos em pesquisa mineral e desenvolvimento de lavra sistemática e organizada.

A esses esforços podem-se agregar os garimpeiros da região, visando ao aproveitamento 
TABELA 5 - Dados comparativos de explotações de diamantes.

\begin{tabular}{|c|c|c|c|c|c|}
\hline ÁREA & $\begin{array}{l}\text { GARIMPO } \\
\text { OU MINA }\end{array}$ & $\begin{array}{l}\text { TEOR } \\
\mathrm{ct} / \mathrm{m} 3\end{array}$ & $\begin{array}{l}\text { TAMANHO } \\
\text { MÉDIO (ct) }\end{array}$ & $\begin{array}{c}\% \mathrm{DE} \\
\text { GEMAS }\end{array}$ & $\begin{array}{l}\text { REFERÊNCIAS } \\
\text { BIBLIOGRÁFICAS }\end{array}$ \\
\hline R. ORANGE (ÁFRICA DO SUL) & M & 0,072 & $0,85-1,3$ & 96 & VAN WIK, PIENAAR (1986) \\
\hline UPPER SMOKE CREEK (AUSTRÁLIA) & M & 8 & - & - & GARLICK (1982) \\
\hline R. JEQUITINHONHA (MG) & M & 0,012 & 0,11 & 80 & ALECRIM (1982) \\
\hline ALTO PARANAÍBA (MG) & G-M & 0,05 a 0,3 & - & - & BARBOSA et al. (1970) \\
\hline ALTO R.S. FRANSCISCO (MG) & G & 0,04 a 0,1 & - & - & BARBOSA et al. (1970) \\
\hline R. PARAGUAÇU (BA) & G & 0,03 & - & - & FRANCO (1975) \\
\hline R. TIBAGI (PR) & G-M & 0,5 & 1 & - & OPPENHEIM (1936) \\
\hline MONTE ALEGRE (PI) & G & 0,01 a 0,08 & - & - & OLIVEIRA, PRAZERES (1983) \\
\hline POXORÉU (MT) & G & 0,04 & - & - & ALMEIDA, ALVES (1983) \\
\hline FRANCA (SP) & G & 0,02 a $0,18(?)$ & 0,3 & $70-80$ & IPT (1990) \\
\hline
\end{tabular}


TABELA 6 - Principais satélites do diamante nos garimpos da região de Franca.

\begin{tabular}{|c|c|c|}
\hline MINERAL OU ROCHA & JARGÃO GARIMPEIRO & PESO ESPECÍFICO \\
\hline Anatásio & chumbada ou sericória & 3,9 \\
\hline Calcedônia & olho de peixe & $2,57-2,64$ \\
\hline Cianita & palha de arroz & $3,56-3,66$ \\
\hline Corindon & campina & $4-4,1$ \\
\hline Crisoberilo & crisota & 3,75 \\
\hline Epídoto & esverdeada & $3,35-3,45$ \\
\hline Goethita (+ quartzo) & canjica & $3,3-4,5$ \\
\hline $\begin{array}{l}\text { Goerceixita } \\
(+ \text { goethita) }\end{array}$ & marumbé & $3,04-3,19$ \\
\hline Granada & granada & $3,5-4,32$ \\
\hline Ilmenita & agulha ou fundinho & 4,7 \\
\hline Itabirito & lacre & - \\
\hline Limonita & feijão & $3,6-4$ \\
\hline Magnetita & $\begin{array}{l}\text { cativo de ferro ou } \\
\text { caboclo lustroso }\end{array}$ & 5,18 \\
\hline Monazita & ogó(?) & $4,6-5,4$ \\
\hline Quartzo & dente de cão ou cristal & 2,65 \\
\hline Rutilo & ferragem & $4,18-4,25$ \\
\hline Sílex & caboclo ou caboclinho & 2,65 \\
\hline Turmalina ou Turmalinito & pretinha & 3,22 \\
\hline
\end{tabular}


de áreas onde a lavra sistemática se mostre inviável; ainda neste caso, a explotação deveria ser legalizada, sob orientação técnica apropriada, buscando sanar os problemas humanos, ambientais e de produção hoje verificados.

\section{AGRADECIMENTOS}

Os autores agradecem a Mirna M. Ferracini pela elaboração da Figura 1, ao Geól. Carlos A. Bistrichi e ao Prof. Fernando F. M. de Almeida pela leitura do manuscrito.

\section{REFERÊNCIAS BIBLIOGRÁFICAS}

ALECRIM, J.D. 1982. Recursos minerais do Estado de Minas Gerais. Belo Horizonte, Metamig. 299 p.

ALMEIDA, F.F.M. de. 1964. Os fundamentos geológicos do relevo paulista. São Paulo, IGG. p. 169-263 (Boletim 41).

1986. Distribuição regional e relações tectônicas do magmatismo pós-paleozóico no Brasil. Revista Brasileira de Geociências, 16 (4):325-349.

ALMEIDA, V.J. de \& ALVES, A.C. 1983. Garimpos de diamantes de Poxoréu - MT. In: SCHMALTZ, W.H., GUIMARÃES, G. (Coord.) Garimpos do Brasil. Brasília, p. 363-378 (DNPM. Avulso, 5).

BARBOSA, O. et al. 1970. Geologia da região do Triângulo Mineiro. Rio de Janeiro, DNPM. 140 p. (Boletim, 136).

COMISSÃO NACIONAL DE ENERGIA NUCLEAR - CNEN. Convênio FFCLRP. 1973. Mapa geológico do nordeste do Estado de São Paulo. Escala 1:50.000

FRANCO, R.R. 1975. As principais áreas diamantíferas do Brasil. Mineração e Metalurgia, 39 (362):46-55.

GARLICK, H.J. 1982. Current status of diamond exploration effort in Australia. 5th Industrial Minerals Int. Congress. p. 205-219.

GONÇALVES, E. \& ALGARTE, J. P. 1988. Programa de desenvolvimento da indústria diamantária na Região Nordeste do Estado de São Paulo - reservas, produção, comércio, indústria de lapidação e capacitação tecnológica. Secretaria da Ciência e Tecnologia, São Paulo, 11 p., Relatório Interno.
HASUI, Y. 1967. Geologia das formações cretáceas do oeste de Minas Gerais. São Paulo. 88 p. (Tese de doutoramento apresentada à Escola Politécnica/USP).

CORDANI, U.G. 1968. Idades potássio-argônio de rochas eruptivas mesozóicas do oeste mineiro e sul de Goiás. In: CONGRESSO BRASILEIRO DE GEOLOGIA, 22․, 1968. Belo Horizonte, Anais... Belo Horizonte, SBG, p. 139-143. et al. 1975. The phanerozoic tectonic evolution of the western Minas Gerais State. Anais da Academia Brasileira de Ciências, Rio de Janeiro, 47(3/4):431-438.

INSTITUTO DE PESQUISAS TECNOLÓGICAS DO ESTADO DE SÃO PAULO IPT. 1990. Programa de desenvolvimento da indústria diamantária do Estado de São Paulo; Primeira fase: diagnóstico preliminar. São Paulo. (IPT, Relatório 28.611).

MARTONNE, E. de. 1940. Problèmes morphologiques du Brésil tropical atlantique. Annales de Géographie, 49 (277):1-27, (278-279):106-129.

OLIVEIRA, F. de \& PRAZERES, W.V. 1983. Garimpos de diamantes da região de Gilbués - Piauí. In: SCHMALTZ, W.H., GUIMARÃES, G. (Coord.). Garimpos do Brasil. Brasília, p. 237-255. (DNPM. Avulso, 5).

OPPENHEIM, V. 1936. Sedimentos diamantíferos do Paraná. Rio de Janeiro. 21 p. (DNPM. Avulso, 9).

VAN WYK, P.P. \& PIENAAR, L.F. 1986. Diamondiferous gravels of the lower Orange River, Namaqualand. In: ANHAUSSER, C.R. MASKE, S. (Eds.) Mineral deposits of southern Africa. Johannesburg: Geol. Soc. S. Afr. v. 2, p. 2.173-2.191. 